\title{
Characteristics and Trends of Chinese Scholars' Publication in High-Level Management Journals
}

\author{
Hongyu Chen, Zitao Qing \\ School of Business Administration, South China University of Technology, Guangzhou, China \\ Email: chenhongyu7@foxmail.com
}

How to cite this paper: Chen, H.Y. and Qing, Z.T. (2019) Characteristics and Trends of Chinese Scholars' Publication in High-Level Management Journals. Open Journal of Social Sciences, 7, 1-17.

https://doi.org/10.4236/jss.2019.711001

Received: October 1, 2019

Accepted: November 1, 2019

Published: November 4, 2019

Copyright $\odot 2019$ by author(s) and Scientific Research Publishing Inc. This work is licensed under the Creative Commons Attribution International License (CC BY 4.0).

http://creativecommons.org/licenses/by/4.0/

(c) (i) Open Access

\begin{abstract}
High level academic journals tend to have strict review procedures and processes. The high level journal papers were also more likely to get a reference. It also makes the priority in the academic competition process. Scholars are more willing to put their own research first appears in the high level of academic journals. So what is the current situation of Chinese scholars publishing high-level journals? What are the characteristics and trends? Taking the field of management as an example, the paper first collects the papers published by Chinese scholars in the list of top journals in the field of management recognized by the international community, and conducts descriptive statistical analysis, including the basic situation of publication, the characteristics of authors and the analysis of international coauthors. Four main conclusions are obtained, which are of certain reference value to summarize the characteristics of high-level journals and objectively judge the development of management research level in China.
\end{abstract}

\section{Keywords}

High-Level Journals, Papers Published, Feature Analysis, International Co-Author

\section{Introduction}

Every scientific research work has a stage of literal expression [1]. Scientific literature is the carrier used by scholars to record knowledge and information [2]. High-level journals are embodied in high-quality papers, high-quality editorial staff and excelsior editorial links. Researchers choose to publish their research papers in high-level journals [3]. On the one hand, it is conducive to the rapid dissemination of research achievements and the expansion of their influence [4]. On the other hand, the "scarcity" of high-level journals enables authors to have 
higher visibility and recognition, increase page views, and thus help improve citations [5].

With the continuous growth of China's comprehensive national strength and scientific and technological strength, the number of papers published by Chinese scholars in journals with international influence has ranked the second in the world in recent 10 years; the number of highly cited papers ranked the third in the world, and the total number of papers produced ranked the second in the world [4] [6]. So what are the publishing characteristics of Chinese scholars in high-level management journals? What are the trends?

In the past, there has been little research on the publishing characteristics of high-level journals, especially in the current academic atmosphere, which attaches great importance to high-level journal papers. Generally, the research on high-level journals tends to focus on the improvement of the level of journals [7] [8], such as English discipline journal, biology discipline journal and so on etc., instead of analyzing and statistics the current publication situation of Chinese scholars. There are relatively few studies on the current trend of publication. This paper is based on the characteristics and trends of the research on high-level journal publication. On the one hand, the further development of the research theory on high-level journal publication is a supplement to the previous research theories. On the other hand, the UT Dallas/management top journals catalogue completed in this paper represents the publication of detailed descriptive statistics of high-level journals, including the analysis of the characteristics of the authors, the analysis of the characteristics of the international co-authors of this paper and other studies, as well as the objective judgment of the development of some reference value management research levels in China.

This paper analyzes the trend of the publication of high-level journals; take management as an example, which is conducive to building a more fair platform for the steady development of scientific research in the future. It is our future direction to encourage more efficient output of high-level results and improve the efficiency of China's scientific research input through statistics of publication [9]. Therefore, the results of this paper can deeply explore the academic potential of scholars and promote their own development, which to some extent promotes the efficiency of China's scientific research investment and scientific research development.

\section{Statistical Analysis}

\subsection{Sample Selection}

Management is introduced from the west and developed in recent years a subject area. Compared with institute of science, the publishing cycle is shorter, paper availability is stronger. In the field of management, there is a list of top journals in the world recognized by the academic community. It is by the journal of the American News and world report's directory, which is the US News rankings, define the 24 kinds of periodical summary as UT/DALLAS economic manage- 
ment class international authoritative journal directory (top) (hereinafter referred to as UT/DALLAS top journals directory), UT/DALLAS top journals directory is also an important reference index to measure management college academic status. The selection of this top-level journal catalog as a research sample meets the requirements of high-level journals and avoids the errors caused by subjective selection of high-level journals.

UT/DALLAS top journals directory includes: 1) Academy of Management Journal; 2) Academy of Management Review; 3) Administrative Science Quarterly; 4) Information Systems Research; 5) Journal of Accounting and Economics; 6) Journal of Accounting Research; 7) Journal of Consumer Research; 8) INFORMS Journal of Finance; 9) Journal of Financial Economics; 10) Journal of International Business Studies; 11) Journal of Marketing; 12) Journal of Marketing Research; 13) Journal of Operations Management; 14) Journal on Computing; 15) Management Science; 16) Manufacturing and Service Operations Management; 17) Marketing Science; 18) MIS Quarterly; 19) Operations Research; 20) Organization Science; 21) Production and Operations Management; 22) Strategic Management Journal; 23) The Accounting Review; 24) The Review of Financial Studies.

As the research object of this paper is high level journal papers, the 24 important international academic journals in UT/DALLAS top journals directory are recognized as high level journals in this field, so this paper USES them as the source of literature retrieval.

The data in this paper come from multiple channels, including Web of science database and scholar's personal homepage. Web of Science database (WoS) is selected as the literature data source. It is a web-based product developed by TOMSON technology information group in the United States [10]. It is a large-scale, comprehensive, multi-disciplinary and core journal citation index database. WoS is considered to be the most comprehensive database, representing mainstream national and international research, covering the most important and influential research results of the world, with a strong representation.

The search strategy selects the advanced search function of Web of Science, which is designed for joint search based on "SO (publication name)" and "AD (address)". For example, "SO = Academy of Management Journal and $\mathrm{AD}=$ China", the retrieval period is all years, the literature type is selected as "article", and the language is "English", the economic Management literature containing Chinese addresses (including mainland China, Hong Kong, Macao And Taiwan) is retrieved and downloaded.

Our initial plan was to measure the publication situation from 1978 to 2018 after China's reform and opening up. In fact, it was 1985 when Chinese scholars first published their academic papers in UT/DALLAS top journals, so we set the research span of this paper as the actual time span from 1985 to 2018. Data and download time are respectively: data from 1985 to 1994 correspond to January 5 to January 14, 2019; data from 1995 to 2004 correspond to January 18 to January 31, 2019; data from 2005 to 2014 correspond to February 10 to February 20, 
2019; data from 2015 to 2018 correspond to February 26 to February 28, 2019. A total of 1797 papers were retrieved. According to the search results, the information of bibliography was collected. This chapter adopts the bibliometrics method to select the 1797 papers retrieved as the research objects, and mainly carries out descriptive statistical analysis from three aspects: first, the basic situation of the samples, second, the characteristics analysis of the authors, and third, the analysis of international coauthors.

\subsection{Basic Information of the Sample}

\subsubsection{General Situation}

Table 1 shows the distribution of the retrieved 1797 academic papers in UT/DALLAS top journals directory, as shown in Figure 1. Among them, Management Science is the journal with the largest number of publications published by Chinese scholars, with 228 papers accounting for $13.09 \%$ of the total publications, followed by Production and Operations Management with 201 papers. In the UT/DALLAS top journals catalogue, Chinese scholars published 6 papers with more than 100 papers, accounting for $25 \%$ of the total number of journals. Chinese scholars published 1091 papers in these 6 journals, accounting for $62.63 \%$ of the total number of publications. The number of articles published in the journal Manufacturing and Service Operations Management is 1, while 8 articles are respectively published in The Review of Financial Studies and Administrative Science Quarterly. There are 14 publications of 10 - 100 articles. There are five kinds of papers published in $100-200$.

\subsubsection{Subject Classification Analysis}

The choice of Chinese scholars to publish periodicals has obvious centrality. Because management involves every field of science, is a broad, all kinds of discipline system, the paper according to the classification of the national natural science foundation in our country, the UT/DALLAS top journals directory classify, divided into management science and engineering, business management, economy three disciplines of science [11], statistics of interdisciplinary scholars in our country in the UT/DALLAS top journals published in the list.

As shown in Figure 2, business administration subjects published 862 papers in UT/DALLAS top journal catalogue, which was the most published subject, accounting for $47.97 \%$, nearly half of the total published. Management science and engineering published 764 articles, accounting for $42.52 \%$ of the total, while economic science published 171 articles, accounting for $9.52 \%$. In the UT/DALLAS top journals directory, the number of journals corresponding to the three disciplines is not exactly equal. There are $8 \mathrm{c}$ kinds of management science and engineering, 13 kinds of business administration and 3 kinds of economic science in UT/DALLAS top journals directory. This is one of the reasons why the subjects published in UT/DALLAS top journals directory mainly focus on business administration. 
Table 1. Distribution of samples in UT/DALLAS top journals directory.

\begin{tabular}{|c|c|c|}
\hline The serial number & UT24 & Search quantity (article) \\
\hline 1 & The Accounting Review & 28 \\
\hline 2 & Journal of Accounting and Economics & 24 \\
\hline 3 & Journal of Accounting Research & 32 \\
\hline 4 & Journal of Finance & 46 \\
\hline 5 & Journal of Financial Economics & 117 \\
\hline 6 & The Review of Financial Studies & 8 \\
\hline 7 & Information Systems Research & 91 \\
\hline 8 & INFORMS Journal on Computing & 61 \\
\hline 9 & MIS Quarterly & 70 \\
\hline 10 & Journal of Consumer Research & 80 \\
\hline 11 & Journal of Marketing & 38 \\
\hline 12 & Journal of Marketing Research & 72 \\
\hline 13 & Marketing Science & 55 \\
\hline 14 & Management Science & 228 \\
\hline 15 & Operations Research & 195 \\
\hline 16 & Journal of Operations Management & 51 \\
\hline 17 & $\begin{array}{c}\text { Manufacturing and Service Operations Man- } \\
\text { agement }\end{array}$ & 1 \\
\hline 18 & Production and Operations Management & 201 \\
\hline 19 & Academy of Management Journal & 103 \\
\hline 20 & Academy of Management Review & 14 \\
\hline 21 & Administrative Science Quarterly & 8 \\
\hline 22 & Organization Science & 33 \\
\hline 23 & Journal of International Business Studies & 141 \\
\hline 24 & Strategic Management Journal & 106 \\
\hline
\end{tabular}

\subsection{Analysis of Author Characteristics}

\subsubsection{Author Quantity Analysis}

The number of authors of a paper can reflect the cooperation in publication [12]. This data is obtained by counting the number of signed authors from the first author of each sample, which is summarized in Figure 3.

UT/DALLAS top journal paper divided by the number of author will be published in China in the field of management in 1985-2018. One by line author has 128 papers, published independently accounted for about $7.23 \%$ of total number of published, it shows that the present our country areas of management of high level papers published still tend to be published, both domestic institutions of cooperation and international cooperation. There are 462 papers produced 


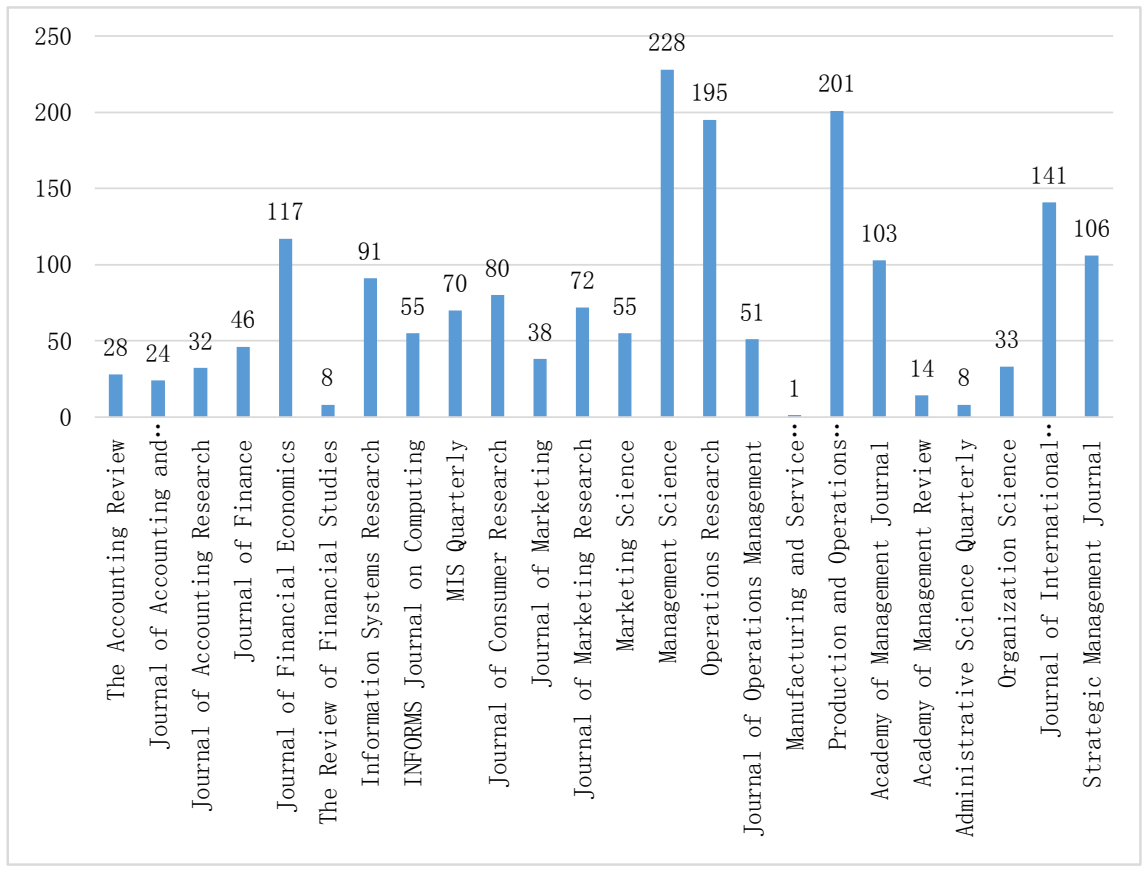

Figure 1. Distribution of samples in UT/DALLAS top journals directory.

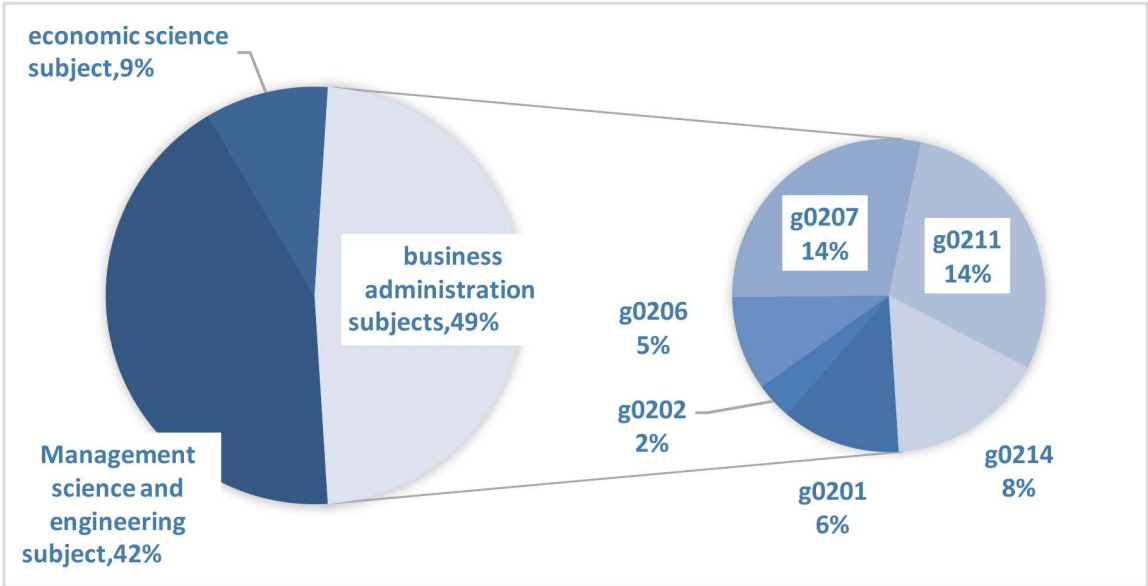

Figure 2. UT/DALLAS top journals directory of publications of various disciplines.

jointly by two scholars, 796 papers with 3 authors, 318 papers with 4 authors, and 93 papers with 5 or more authors.

In the field of management in our country UT/DALLAS top journals published by the author after the classification number as shown in Figure 3, the distribution of scholars in the field in our country management high level journal papers published is given priority to with three of the author's cooperation, this part of the paper accounts for about 1985-2018. Chinese academics published UT/DALLAS top journal paper, $45.69 \%$ of the total, is the most common form of cooperation. The second is the joint output of the two scholars, a total of 462 papers published. When the number of authors exceeds six, the number of high-caliber papers produced drops sharply. The possible reason is that, as the 


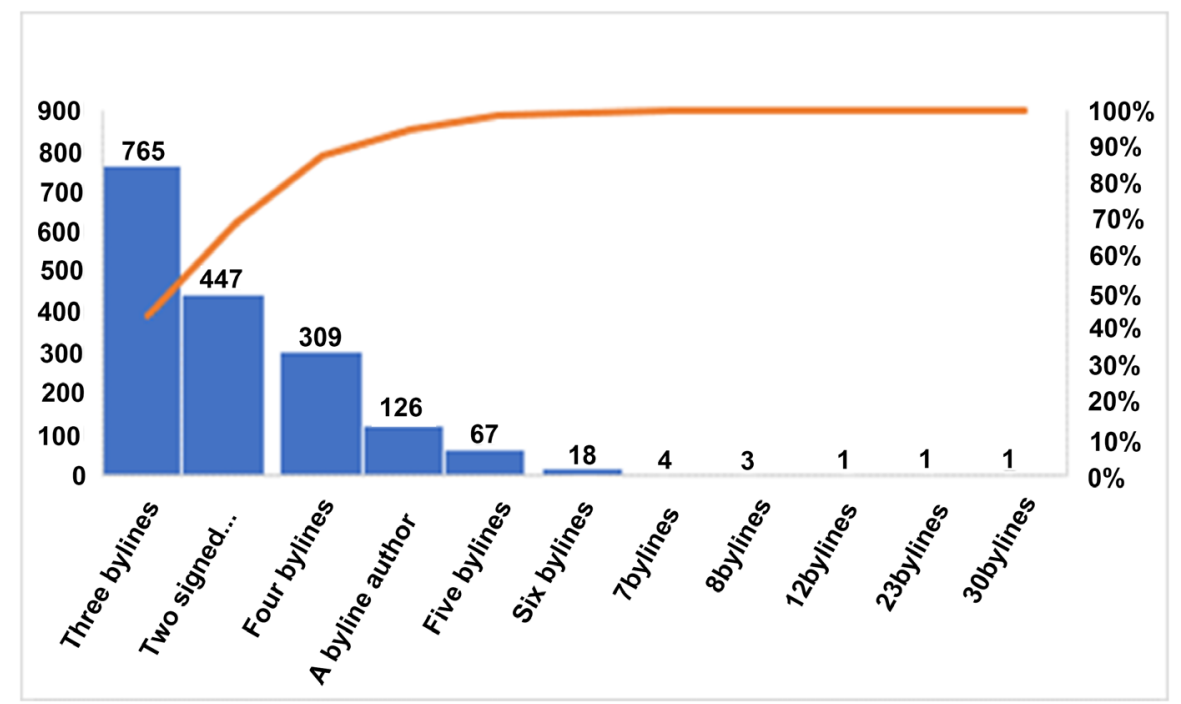

Figure 3. Author distribution diagram.

number of co-authors increases, more communication costs are required in the cooperation process.

\subsubsection{Author Geographical Analysis}

As shown in Figure 4, scholars in mainland China published 57 academic papers independently during the period from 1985 to 2018, accounting for the least 3.17\%, while scholars in Hong Kong, Macao and Taiwan published 190 academic papers independently, more than three times as many as scholars in mainland China. The dramatic increase in cooperative research activities in various research fields has become an indisputable fact, but there is still room for individual research activities. The scholar, deB. Beaver, has explored the reasons for the existence of a single paper from a sociological perspective. According to the history of scientific egoism, for an individual's academic status to be recognized, an important part of his research results must undoubtedly belong to him personally. Therefore, it is not surprising that the monograph exists and enjoys a special reputation [13]. This shows that the research level of Chinese scholars in the field of management is generally lower than that of scholars in Hong Kong, Macao and Taiwan. Independently under Chinese author's total of 247 academic theses, the scholars in mainland accounted for only $23 \%$ of them, it shows that scholars in mainland China and Hong Kong, Macao and Taiwan regions and scholars in the field of management of academic development gap, and in the category of the academic papers published jointly, mainland China and Hong Kong, Macao and Taiwan regions scholars together to 95 the number of published articles, this shows that in cooperation with the mainland scholars, mainland scholars tend to academic cooperation with Hong Kong, Macao and Taiwan regions.

In terms of cooperation with foreign scholars, 481 and 743 papers were written by Chinese mainland scholars, Hong Kong, Macao and Taiwan scholars and 


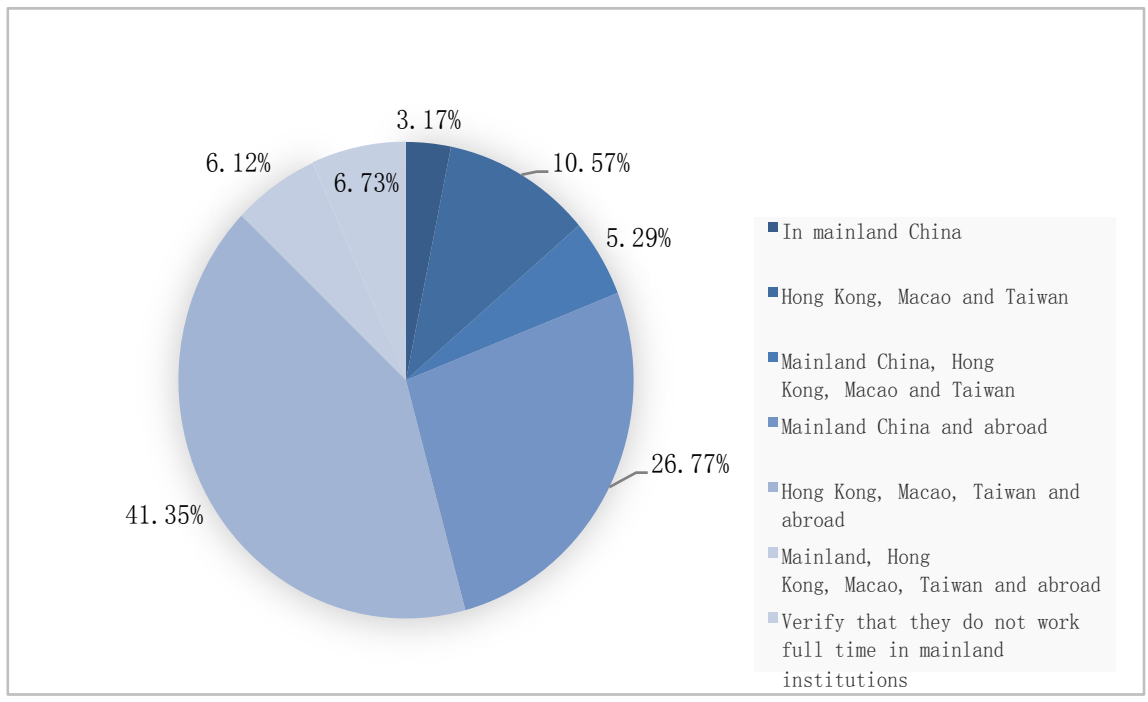

Figure 4. Geographical distribution of authors.

foreign scholars, accounting for $26.77 \%$ and $41.35 \%$ respectively. 110 papers were written by Chinese mainland scholars, Hong Kong, Macao and Taiwan scholars and foreign scholars. The above three types of cooperation accounted for $74.23 \%$ of the total. This shows that both Chinese mainland scholars and Hong Kong, Macao and Taiwan scholars are more inclined to conduct scientific exchanges with foreign scholars.

\subsubsection{Time Series Publication Analysis}

The volume of chronological literature is an indicator that can reflect the actual output of the field of concern and the trend of change and development. Figure 5 shows the chronological distribution of all subjects, including mainland China, mainland China and Hong Kong, Macao and Taiwan regions, mainland China and foreign countries, Hong Kong, Macao and Taiwan regions, Hong Kong, Macao and Taiwan regions and foreign countries, as well as those who are not working full-time in mainland China institutions.

From 1985 to 2018, a total of 1797 papers were published in UT/DALLAS internationally recognized authoritative journals in management field, among which 743 were published by scholars in mainland China (excluding scholars from Hong Kong, Macao and Taiwan). In China it is 1985 for the first time in UT/DALLAS economic Management class internationally recognized authoritative journal "Journal of Management Science" published papers, entitled "An Improved Successive Linear-Programming Algorithm", it is China scholars Jianzhong of Shanghai normal university, the research achievements of Zhang. In 1994, scholars in Hong Kong published their first paper in the UT/DALLAS top journals directory, independently. Since 1997, scholars from Hong Kong, Macao and Taiwan have been ahead of those from mainland China in the number of publications, which has led to an increase in the number of effective 


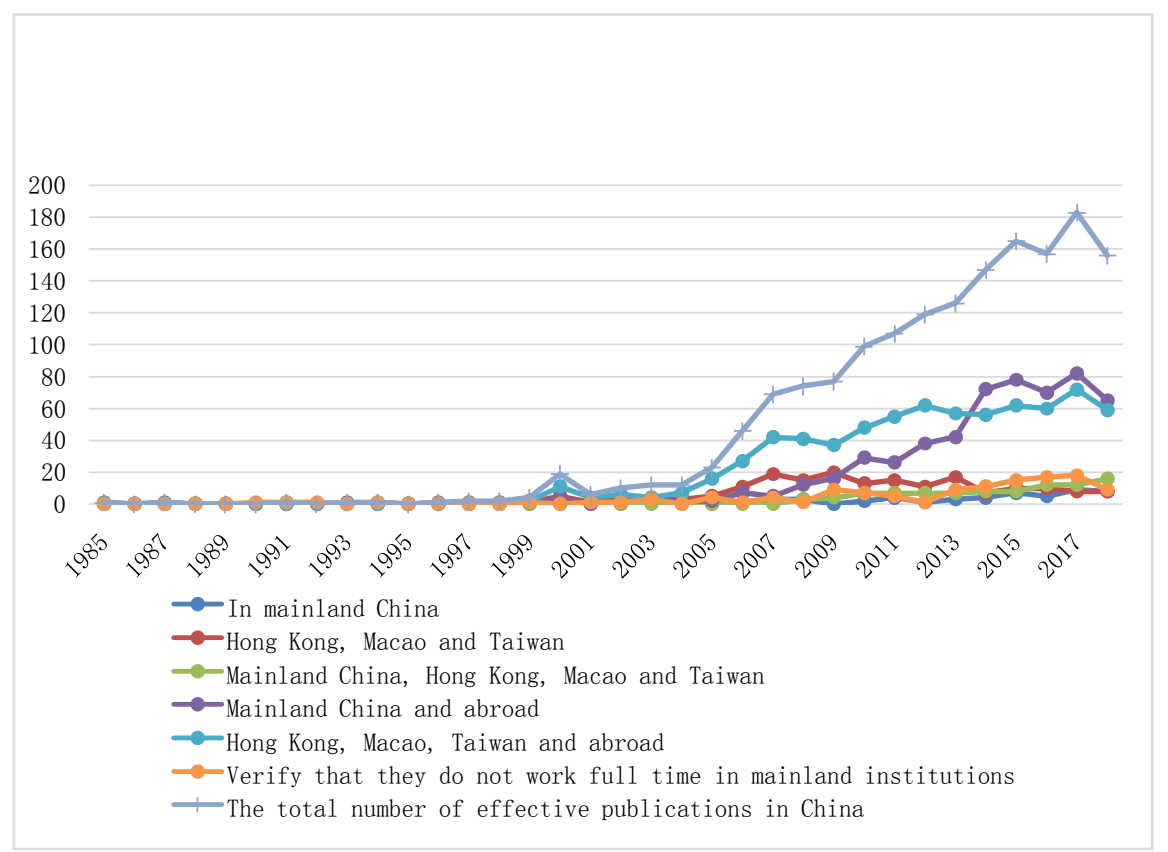

Figure 5. Distribution map of publications in the period.

publications in China. However, there was no significant change in the output of high-level journals from 1985 to 2002. In 2000, Hong Kong reached a small academic peak in the field of management science, publishing 5 academic papers independently and 11 papers in cooperation with foreign scholars. For the first time, the annual number of papers published by Chinese scholars in UT/DALLAS top journals exceeded single digits, reaching 19, although the number of articles published by mainland scholars reached 3 for the first time. Since 2006, both the number of articles published in mainland China and the number of articles published effectively in China have started to grow steadily, while the high level of articles published in Hong Kong, Macao and Taiwan regions have shown fluctuating growth.

In 2014, the number of publications in mainland China was 85 , and the number of publications published by mainland scholars exceeded half of the total number for the first time, which indicates that the number of publications published by mainland scholars exceeded that of scholars in Hong Kong, Macao and Taiwan for the first time, and the number of publications published by mainland scholars reached the highest proportion in the total number of publications. As shown in Figure 3, Figure 5, from 2008 to 2018, the number of articles published in mainland China increased steadily. Especially after 2013, both scholars from Hong Kong, Macao and Taiwan as well as foreign scholars witnessed a substantial and steady increase. By the end of 2018, the number of papers published by mainland scholars had maintained an overall momentum of growth and maintained a leading position in the total number of effective publications.

Here's some comparison and analysis. In comparison with the independent publication in mainland China and Hong Kong, Macao and Taiwan, scholars in 
Hong Kong, Macao and Taiwan independently published 5 academic papers in UT/DALLAS top journals catalogue in 2000, which was surpassed by scholars in mainland China only in 2015. Chung et al. (2009) point out that collaborating with people from the same institution does not improve or degrade the quality of the paper [14]. The publication of articles by scholars in mainland China represents the research level in mainland China. Although they belong to the same country, it is undeniable that scholars in Hong Kong, Macao and Taiwan regions are ahead of scholars in the field of management.

The first collaboration between scholars from mainland China and Hong Kong, Macao and Taiwan came into being in 2001, and was led by Hong Kong scholars, who were both the corresponding author and the first author, while scholars from mainland China were the second author. The second collaboration only began in 2008 , and the number of co-authored papers grew steadily at a low rate, to 16 in 2018.

In 1993, for the first time, scholars from mainland China cooperated with other countries to publish their papers in UT/DALLAS, an internationally recognized authoritative journal of economic management, and published a paper in Operations Research. The co-author country was the United States, and Chinese scholar Ying Li was the fourth author. However, the number of co-authored works between mainland scholars and foreign scholars has been on the rise since 2000, and exceeded the number of co-authored works between Hong Kong, Macao and Taiwan regions and foreign scholars for the first time in 2014. Up to now, the number of co-authored works between mainland scholars and foreign scholars has maintained the largest proportion in the total number of effective publications in China.

The cooperation between Hong Kong, Macao and Taiwan scholars and foreign scholars began in 1997, and has been growing steadily since then, which has driven the growth of the total number of effective publications in China for a long time. The total number of effective publications in China reached a peak of 196 in 2017, and the number of co-authorship between mainland China, Hong Kong, Macao and Taiwan regions and foreign countries also reached a peak.

\subsubsection{Employer Analysis of Mainland Chinese Authors}

The number of papers published in mainland China, either independently, in cooperation with Hong Kong, Macao and Taiwan, or in cooperation with foreign scholars, was 743. In mainland China, we divide it into three types: "project 985" universities, "project 211" universities, and other universities and institutions [15]. It is generally considered that the universities selected into "project 985" and "project 211" belong to research-oriented universities.

As shown in Figure 6, the largest number of "985 project" universities, two-thirds of the total number of samples, such as Tsinghua university, Zhejiang university, Beijing university, and "211 project" university and other universities and institutions is a joint account for about one-third of the number of "211 project" give priority to with Shanghai university of finance and economics 


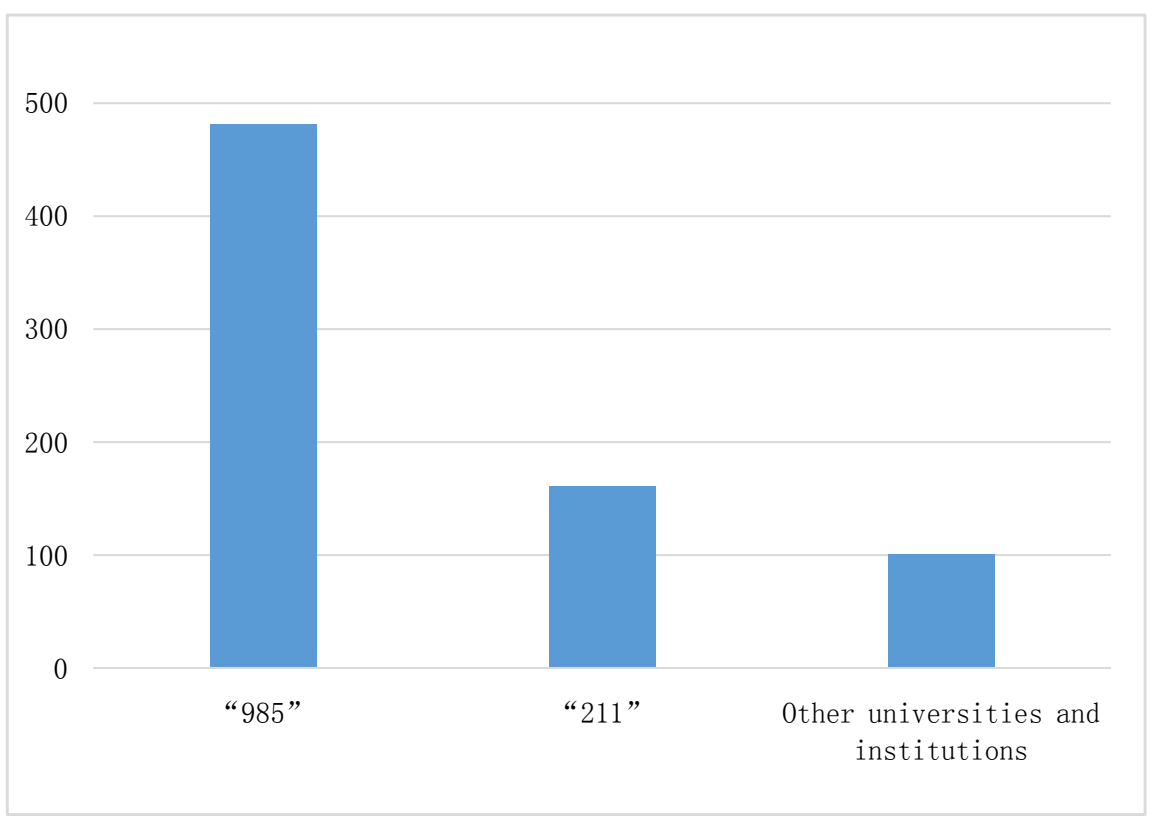

Figure 6. Classification of subjects published in mainland China.

colleges and universities, colleges and other institutions is given priority to with the China Europe international business school.

\subsection{Analysis of Characteristics of International Collaboration in Mainland China}

\subsubsection{Analysis of Characteristics of International Co-Authorship in Mainland China}

According to Figure 5, there are many authors who have completed the paper writing in the form of international co-authorship. Therefore, the author who has conducted international co-authorship is analyzed in the following part.

In 1993, Chinese scholars cooperated with the United States to publish an article titled "Numerical-Solution of Continuous State Dynamic Programs Using Linear and Spline Interpolation", which was published on Operations Research. It was the first paper co-published by domestic and foreign scholars on UT/DALLAS top journals catalogue.

Over the years, international cooperation in management and other fields has developed rapidly, and many excellent international co-authored papers have been published. According to the classification standard proposed by researcher Maria Bordons [16], international co-authored papers are defined as the presence of at least one foreign address in the author's address. According to the definition of co-author, all samples were divided into independent publication and international co-author groups.

According to statistics, from 1985 to 2018, a total of 743 papers were published by mainland scholars in UT/DALLAS top journals of management field, among which 591 were co-authored with researchers from other countries. Specific annual data show that since 2005, the number of papers published in 
UT/DALLAS top journal catalogue in management field in China has increased rapidly. Two papers were published in UT/DALLAS top journal catalogue in 2005, and the number rose to 96 in 2018, among which the number reached the highest in 2017, with an average annual increase of about $441.67 \%$.

As shown in Figure 7, compared with the independent publication group, the number of papers published by the international co-authored group in the field of management in China increased more significantly in the same period. The number of papers published by the international co-authored group in 2005 was 2 , but in 2018 it reached 65, with an average annual growth rate of $225 \%$. The number of international co-authored papers in each year accounted for a relatively stable proportion in the number of papers published in UT/DALLAS top journals directory that year, basically maintaining between $70.0 \%$ and $80.0 \%$. The above data show that the communication and cooperation between researchers in different countries will not only promote scholars to continue in-depth research, but also help scholars to produce more innovative research results.

\subsubsection{Analysis of Geographical Distribution of International Co-Authors} According to the statistical results, a total of 91 countries/regions (hereinafter referred to as "countries") co-authored and published papers of UT/DALLAS top journals in the field of management with China, which are distributed in all continents of the world, indicating that China has established a scientific and technological cooperation network covering the whole world in the field of management.

Figure 8 shows that among the cooperation between China and various regions, mainland China has the largest proportion of papers published in

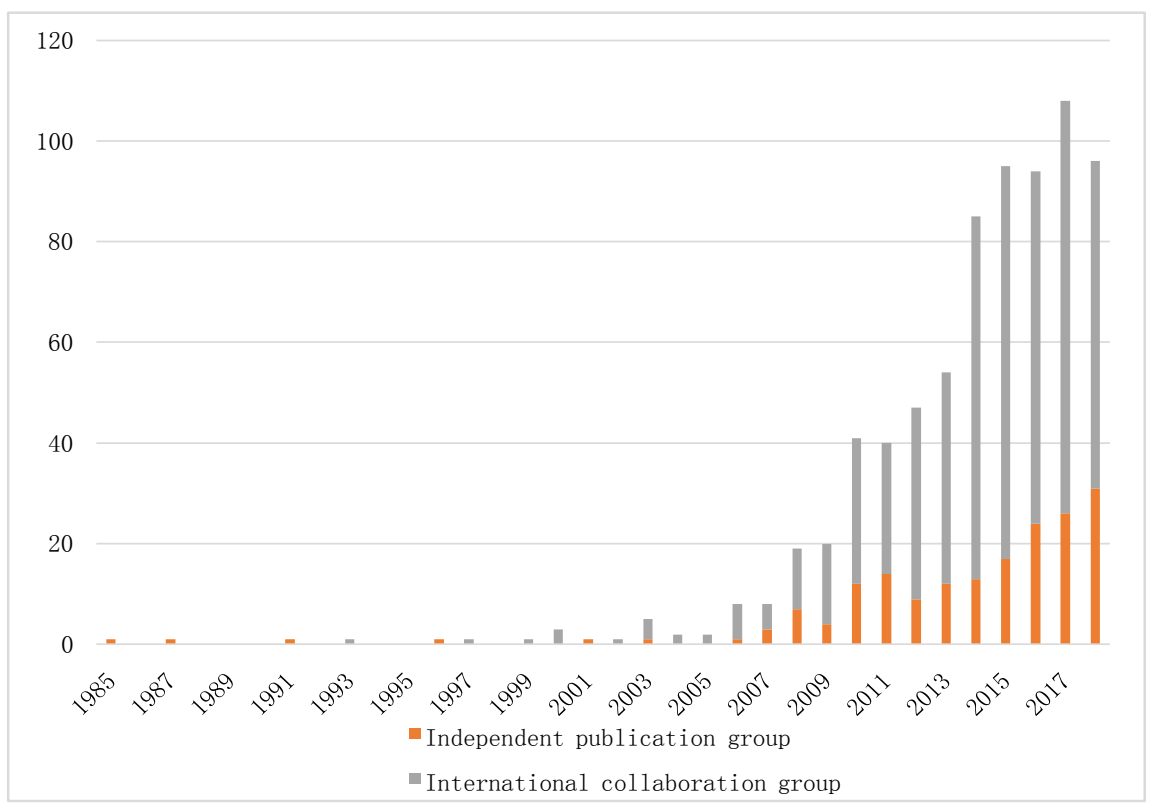

Figure 7. Distribution diagram of the publication proportion of international and non-international co-authored articles. 


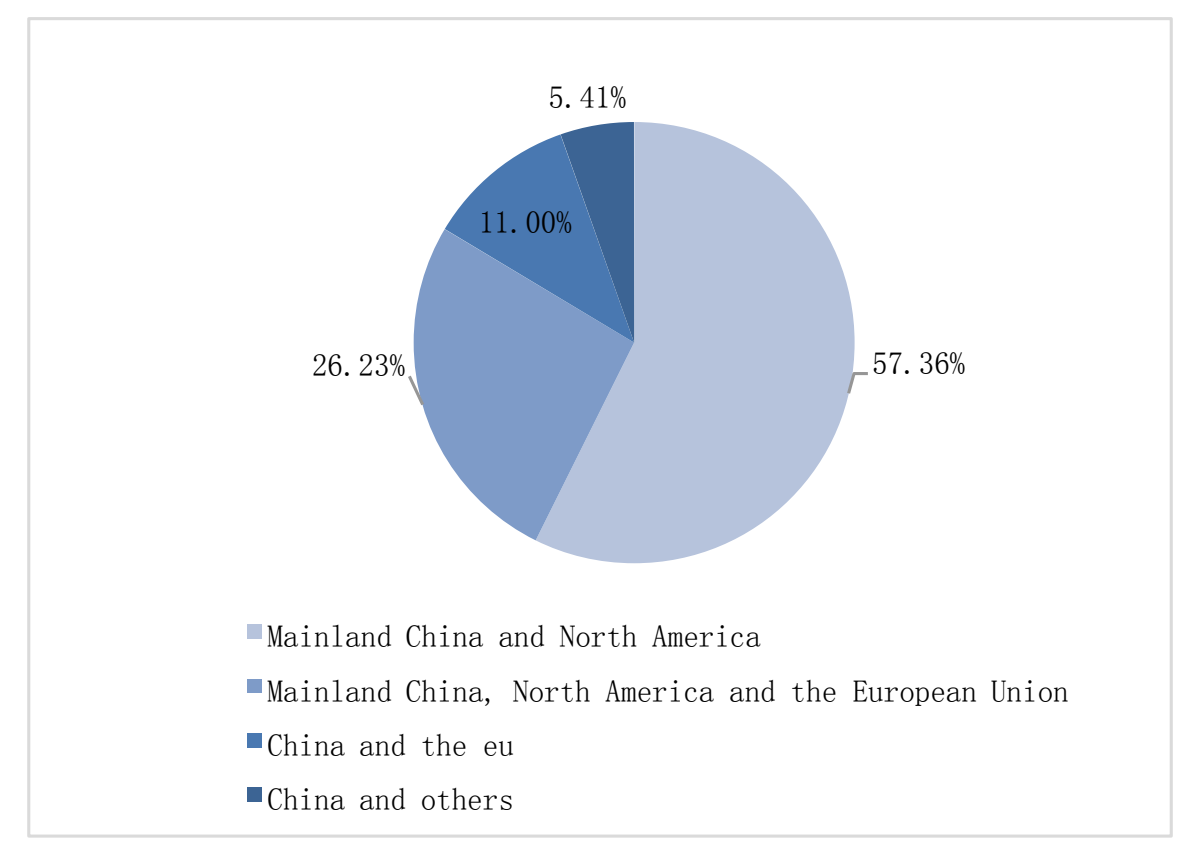

Figure 8. Co-authorship between mainland China and other regions of the world.

UT/DALLAS top journals catalogue in cooperation with north American countries alone, more than half of the total number of papers published in cooperation, reaching 339. The second is the cooperation among mainland China, north American countries and EU countries, accounting for $26.23 \%$ of the total. The third is the cooperation between China and the EU, China and other countries. Generally speaking, the cooperation between mainland China and North American countries is relatively close, accounting for more than $80 \%$. North America and the European Union are still the core of scientific research in the field of management.

\subsubsection{Quantitative Analysis of Co-Authored Countries}

It has been more than 40 years since China launched its reform and opening-up policy in the late 1970s. The number of co-authored countries of a country's international co-authored papers reflects the degree of the country's participation in multilateral scientific cooperation. This section only discusses the situation that the published subjects are mainland Chinese scholars, excluding the cooperation of scholars from Hong Kong, Macao and Taiwan. As shown in Figure 9, from 1985 to 2018, the number of cooperating countries of mainland scholars increased significantly. In 1993, China successfully published the UT/DALLAS top journals catalogue of domestic and foreign scholars for the first time.

In 2009, the number of cooperating countries peaked at 23. However, in that year, the paper with the largest number of cooperative countries appeared in the sample, which was co-authored by 23 countries including China. After removing the outliers, the number of co-authored countries after removing the paper was 5. After 2009, the number of cooperative countries increased steadily. In 2015, 


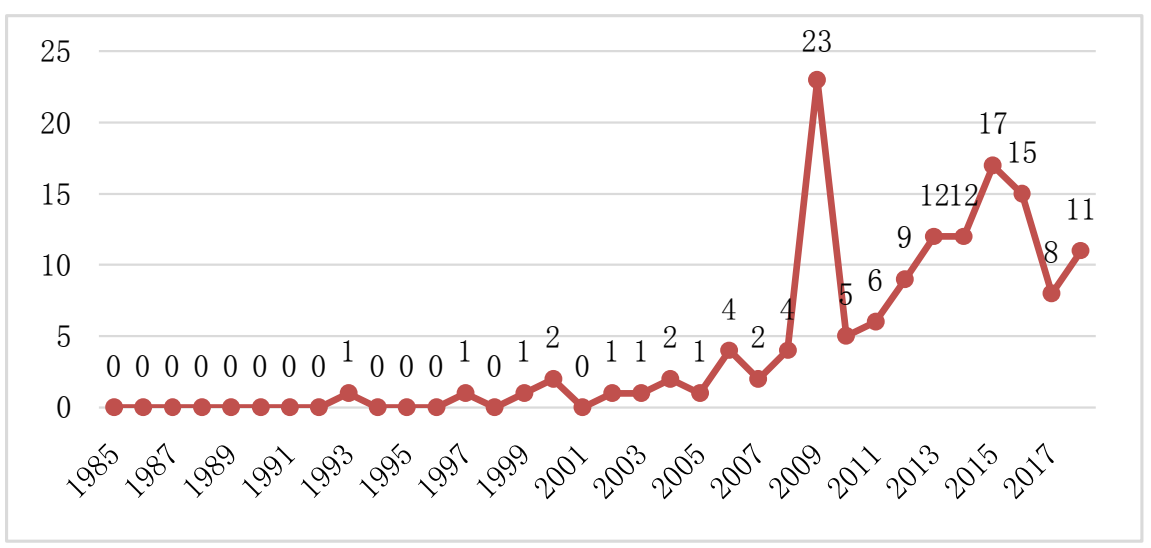

Figure 9. Number of cooperative countries.

the number of cooperative countries was 17 at the same time. After that, the number of cooperative countries declined, and the overall trend of fluctuation was rising. The reason may be related to the turbulence of the international situation from 2015 to 2017, while the construction of friendly relations between countries along the "One Belt and One Road" in 2018 led to the recovery of the number of cooperative countries [17].

To understand the cooperation between China and the major knowledge producing countries and regions in the world, we used the number of countries to evaluate the degree of international co-authorship. At the same time, it can objectively reflect the importance of international scientific and technological cooperation in this field [18]. According to statistics, as shown in Figure 10, in the sample, the co-authorship situation is dominated by bilateral co-authored papers. Among the effective published samples, 981 academic papers were completed jointly by scholars from two countries, accounting for over $60 \%$ of all the samples. There were 301 academic papers written by the same country and 20 by four or more countries. This indicates that the publication of academic papers by Chinese scholars in UT/DALLAS top journals directory is mainly the cooperation between two countries, and then three countries when there are more than three countries, the number of papers produced in UT/DALLAS top journals directory is less and the efficiency is lower.

\section{Conclusions and Discussion}

Based on the above analysis of top UT/DALLAS journals published by Chinese scholars, the characteristics are summarized as follows:

1) In the UT/DALLAS top journals catalogue, Chinese scholars published papers in six journals, accounting for more than $60 \%$ of the total publications. This shows that the publication of UT/DALLAS top journals directory by Chinese management scholars is a pattern of wide distribution and obvious concentration.

2) From the perspective of disciplines, the discipline with the most published articles is business administration. In addition to the high research level of 


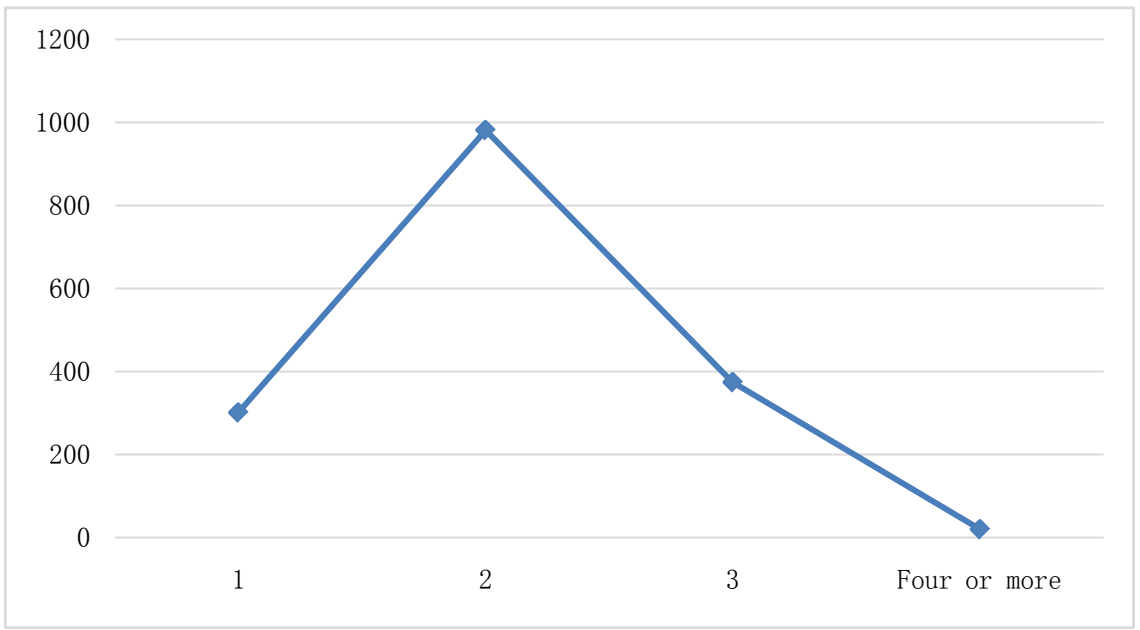

Figure 10. The number of countries to which each sample belongs.

business administration, it is also related to the largest number of journals of business administration. The total number of articles published of economic sciences subject is relatively low, which indicates that the development of economic sciences in China is still insufficient. In this respect, Chinese scholars still need to make more efforts to fill this gap.

3) From the perspective of author characteristics, when the number of authors of a paper is two or three, the cooperative effect is better. When the number of authors exceeds six, the number of high-caliber papers produced drops sharply. The ability of mainland Chinese scholars to independently produce papers of high-level journals is relatively weak. Compared with the cooperation with mainland scholars, mainland scholars are more inclined to cooperate with scholars from Hong Kong, Macao and Taiwan. Both Chinese mainland scholars and Hong Kong, Macao and Taiwan scholars are more inclined to conduct scientific exchanges with foreign scholars. The results of cooperation between Chinese mainland scholars and foreign scholars have been published in all UT/DALLAS top journals, which shows that the cooperation results achieved in this form are the best. Among mainland authors, scholars from "project 985" universities are more likely to publish in high-level journals. This phenomenon indicates that the access of favorable resources to colleges and universities is likely to help scholars produce high-quality results.

4) Communication and cooperation between researchers from different countries can help scholars produce more innovative research results. The mainland of China has established a network of management science and technology cooperation covering the whole world. North America and the European Union are the core areas of scientific research in the field of management at present. The number of countries that China cooperated with entered a stage of rapid growth in 2006, and fell into a trough and began to rise in 2015-2018. Chinese management scholars still need to expand the scope of international cooperation and enhance the strength and depth of multilateral cooperation. 
Based on the above analysis and research, we find that, first, taking UT/DALLAS top journals catalogue as an example, the number of publications of Chinese scholars in the field of management started to increase significantly from 2006 and showed a trend of fluctuating growth. In recent years, the number of publications in mainland China has exceeded that in Hong Kong, Macao and Taiwan, which also reflects the progress in management in mainland China. However, there is the problem of subject development and differentiation. The main subjects of publication in mainland China are 985 universities and colleges, and the types of publication are mainly in cooperation, especially in international cooperation. In recent years, the number of countries cooperating with China has been increasing. At the same time, China is consolidating the existing international cooperative relations, but there is still room for learning and progress.

\section{Conflicts of Interest}

The authors declare no conflicts of interest regarding the publication of this paper.

\section{References}

[1] Kreber, C. (2002) Controversy and Consensus on the Scholarship of Teaching. Studies in Higher Education, 27, 151-167. https://doi.org/10.1080/03075070220119995

[2] Boyer, E.L. (1990) Scholarship Reconsidered: Priorities of the Professoriate. Jossey-Bass San Francisco, CA, 33.

[3] Barney, J.B. (1991) Firm Resources and Sustained Competitive Advantage. Journal of Management, 17, 99-120. https://doi.org/10.1177/014920639101700108

[4] China Institute of Science and Technology Information (2017) Press Release of Statistical Results of Chinese Scientific and Technological Papers 2017. Press Release of Statistical Results of Chinese Scientific and Technological Papers.

[5] (2010) Definition and Characteristics of Sci-Tech Journals. Chinese Journal of Modern Medicine, 12, 88.

[6] China Institute of Science and Technology Information (2017) Output Status of Chinese International Scientific and Technological Papers in 2017. Press Conference on Statistical Results of Chinese Scientific and Technological Papers.

[7] Garfield, E. (1955) Citation Indexes to Science: A New Dimension in Documentation through Association of Ideas. Science, 122, 108-111. https://doi.org/10.1126/science.122.3159.108

[8] Garfield, E. (2006) The History and Meaning of the Journal Impact Factor. The Journal of the American Medical Association, 295, 90-93. https://doi.org/10.1001/jama.295.1.90

[9] Hirsch, J.E. (2005) An Index to Quantify an Individual's Scientific Research Output. Proceedings of the National Academy of Sciences of the USA, 102, 16569-16572. https://doi.org/10.1073/pnas.0507655102

[10] Wildgaard, L., Schneider, J. and Larsen, B. (2014) A Review of the Characteristics of 108 Author-Level Bibliometric Indicators. Scientometrics, 101, 125-158. https://doi.org/10.1007/s11192-014-1423-3

[11] Zheng, Z.L. (2019) Strategic Analysis of Regional Innovation and Development in Sci-Tech Journals. Journal of North China University of Water Resources and Hy- 
dropower (Social Science Edition), No. 4, 31-35+97.

[12] Beaver, D. and Rosen, R. (1979) Studies in Scientific Collaboration Part III -Professionalization and the Natural History of Modern Scientific Co-Authorship. Scientometrics, 1, 231-245. https://doi.org/10.1007/BF02016308

[13] Chung, K.H., Cox, R.A.K. and Kim, K.A. (2009) On the Relation between Intellectual Collaboration and Intellectual Output: Evidence from the Finance Academe. Quarterly Review of Economics and Finance, 49, 893-916. https://doi.org/10.1016/j.qref.2008.08.001

[14] Newman, M.E.J. (2001) Scientific Collaboration Networks (I): Network Construction and Fundamental Results. Physical Review, 64, Article ID: 016131. https://doi.org/10.1103/PhysRevE.64.016131

[15] Newman, M.E.J. (2001) Scientific Collaboration Networks (II): Shortestpaths, Weighted Networks and Centrality. Physical Review, 64, Article ID: 016132. https://doi.org/10.1103/PhysRevE.64.016132

[16] Piette, M.J. and Ross, K.L. (1992) An Analysis of the Determinants of Co-Authorship in Economics. Journal of Economic Education, 23, 277-283. https://doi.org/10.1080/00220485.1992.10844762

[17] Yao, S. (2019) Reform and Development: Review and Prospect of International Development Cooperation in 2018. International Economic Cooperation, No. 1, 29-37.

[18] Bordons, M., Gomez, I., Fernandez, M.T., Zulueta, M.A. and Méndez, A. (1996) Local, Domestic and International Scientific Collaboration in Biomedical Research. Scientometrics, 37, 279-295. https://doi.org/10.1007/BF02093625 